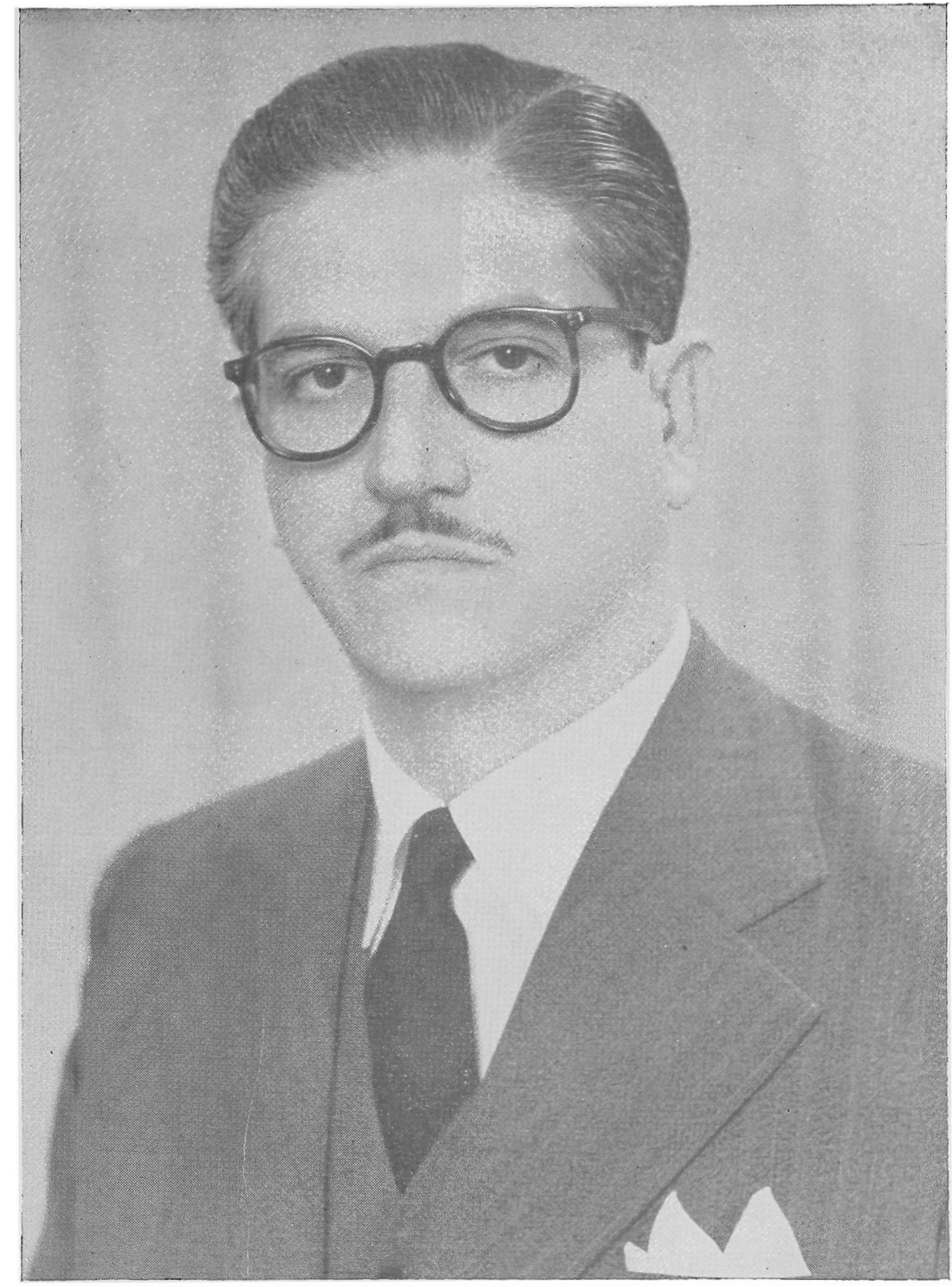

Prof. ALFREDo BUZAID, novo catedrátice de Direito Judiciário Civil. 


\section{Professor Alfredo Buzaid - Novo titular da Cátedra de Direito Judiciário Civil.}

O Prof. Alfredo Buzaid nasceu na cidade de Jaboticabal, Estado de São Paulo, no dia 20 de julho de 1914. Fêz o curso primário e secundário no Ginásio São Luiz de Jaboticabal, dirigido pelo Prof. Aurélio Arrobas Martins, bacharelando-se no ano de 1930. Sua inclinação pelas letras despertou cêdo. Cursava o quarto ano do ginásio, quando entrou para o corpo de redação do jornal publicado pelo Centro Joaquim Nabuco. No quinto ano ginasial, encerrando o curso denominado de bacharelado, foi eleito orador oficial das três turmas de reservistas, respectivamente do Ginásio, da Escola de Farmácia e da Escola de Odontologia.

Ingressou na Faculdade de direito de S. Paulo em 1931. Prossegue sua atividade de jornalista, escrevendo especialmente para "O Combate" de Jaboticabal e depois para "A Gazeta Comercial", da qual foi diretor. Concluído o curso acadêmico, advogou dois anos e meio em Jaboticabal, transferindo-se para São Paulo em fins de 1938. Desde então revelara seu interêsse pelos estudos de direito processual civil, publicando em 1939 um artigo sôbre "Despacho Saneador" na Revista Judiciária.

Quando Enrico Tullio Liebman iniciou seu curso de extensão universitária na Faculdade de Direito, foi Alfredo Buzaid um dos mais assíduos frequentadores, tornando-se em pouco amigo pessoal do notável mestre italiano.

Em 1943 publicou seu primeiro livro — Da Ação Declaratória no Direito Brasileiro, com que se inicia a Coleção de Estudos de Direito Processual Civil, dirigida pelos professôres S. Soares de Faria e Enrico Tullio Liebman. Inscreve-se em 1945, com a monografia - Do Agravo de 
Petição no Sistema do Código de Processo Civil - no curso ̀̀ docência livre, tendo sido aprovado e nomeado no dia 17 de agôsto de 1946.

Publicou até 1951 os seguintes trabalhos: Da Apelação Ex Officio; Paula Batista (Atualidades de um velho processualista); e A Escola de Direito de Beirute. Em 1952 inscreve-se no concurso à cátedra de Direito Judiciário Civil na Faculdade Paulista de Direito da Pontificia Universidade Católica de S. Paulo, apresentando a monografia denominada - Do Concurso de Credores no Processo da Execução. Venceu o concurso, obtendo a média 9,9. Foi nomeado e empossado no dia 23 de maio de 1953.

Tem publicado pareceres e artigos de doutrina na Revista dos Tribunais, na Revista Forense e na Revista Jurídica. Participou de Comissão Julgadora de concurso à cátedra de Direito Judiciário Civil nas Universidades de Belo Horizonte, Porto Alegre e do Rio de Janeiro (Univer. sidade do Brasil). Pertence à Associação Italiana de Pro cesso Civil, com sede em Florença e é membro do Instituta Ibero-Luso-Filipino e Americano de Processo Civil, com sede em Madrí. É conselheiro da Revista de Derecha Processal Civil, editada em Madrí; sob os auspicios do re. ferido Instituto Publicou ainda a monografia - Da Açã Direta de Declaração de Inconstitucionalidade no Direito Brasileiro.

Em 1957 inscreveu-se, na Faculdade de Direito da Universidade de S. Paulo, no concurso à cátedra de Direito Judiciário Civil, vaga com o falecimento do Prof. Benedito de Siqueira Ferreira. Sua monografia se denomina -- Da Ação Renovatória de Contrato de Locação de Prédio Des. tinado a Fins Comerciais ou Industriais. Alcançou distinção em tôdas as provas e com todos os examinadores, tendo sido nomeado e empossado na cadeira no dia 8 de maio de 1958, em sessão solene da Congregação. 


\section{Saudação do Professor Miguel Reale}

Introduzido no recinto pelos professôres Braz de Sousa Arruda, Honório Monteiro e J. C. de Ataliba Nogueira, após as cerimônias de estilo foi o novo professor saudado em nome da Congregação pelo professor Miguel Reale que proferiu a seguinte oração:

“Esta reunião solene da douta Congregação da Faculdade de Direito de São Paulo tem o significado de uma confirmação, de uma crisma para quem, como V.Exa., já passou, brilhantemente, pelo batismo das provas de concurso. Em alguns casos, o exame para a Cátedra, é uma prova de fogo, ou de iniciação. No seu caso particular ao contrário, não marcou senão o têrmo final de uma ascenção natural, após terem sido vencidos os obstáculos com perseverança e com método.

$O$ ingresso de V.Exa., laureado, como catedrático, não constituiu surprêsa para ninguém.

Já se podia mesmo antever tal resultado no jovem que freqüentava os bancos acadêmicos por volta de 1933 e 1935. Posso, pessoalmente, dar testemunho da seriedade de seus propósitos desde o início de seus estudos. Lembro-me bem quando, juntos, iamos ao longo da Avenida Brigadeiro Luís Antônio trocando idéias sôbre os problemas fundamentais da cultura e formulando observações e críticas sôbre as questões basilares da nossa Pátria. Desde logo impressionou-me o caráter severo de sua personalidade.

Numa terra onde se ama tanto a improvisação, onde se confia demasiadamente nos poderes da intuição, V.Exa. preferiu seguir a trilha difícil, mas segura, dos estudos metódicos, da perquirição disciplinada, confiante na ação do tempo, segundo o velho e sempre ensinamento de Leonardo Da Vinci: "A verdade só é filha do tempo"

A seriedade que orna a sua personalidade, meu caro amigo Alfredo Buzaid, é de dúplice natureza, ao mesmo tempo moral e intelectual: moral, pela fidelidade aos prin- 
cípios que estruturam o caráter e fazem convergir para critérios constantes de referência o complexo das atitudes; e intelectual, pela fidelidade aos valores do espírito integrando-os em uma síntese racional, indispensável aos homens verdadeiramente cultos.

$\mathrm{Na}$ realidade, a cultura não pode ser concebida senão como a vibratilidade do espírito perante todos os motivos que possam ser de interêsse para os homens, desde os mais insignificantes da vida cotidiana, até àqueles que, transcendendo as nossas preocupações imediatistas, nos entreabrem os horizontes da Humanitas na história e nos permitem vislumbrar as perspectivas do que se situa além das coordenadas delimitadoras do espaço e do tempo.

Como assinalou o seu mestre Francesco Carnelutti, o jurista que não conhece senão o Direito, é uma pobre e triste coisa. Foi antecipando a êste reconhecimento de um cultor da ciência processual, que V.Exa. se dispôs a uma formação metódica, absolutamente indispensável a quem se destina à carreira do magistério.

Inspirado por um dedicado professor de sua querida Jaboticabal, V.Exa., ainda jovem, se afeiçoou aos estudos da Filosofia, da Sociologia e da Política, tornando-se um amante dos clássicos da língua, procurando, assim, paulatinamente, burilar os utensílios indispensáveis às atividades da nobre arte do Direito, expressão viva de uma ciência tôda feita de cautelas e de prudências. Êsse amor pelas raízes de nossa cultura lusíada ia ter influência decisiva no jurisconsulto que esta Casa hoje festivamente recebe. Se V.Exa. é justamente reconhecido como uma das maiores expressões do Direito Processual em todo o continente americano, e se já se fala hoje, com acêrto, na "Escola Paulista de Direito Processual", isto se deve a uma síntese que V.Exa. e seus companheiros estão sabendo realizar, síntese esta caracterizada pela integração harmoniosa de elementos universais, comuns a todos os processualistas do mundo ocidental, e de elementos peculiares à tradição de nossa Jurisprudência. 
O nosso mestre Alberto Torres, sôbre cujas obras tanto meditamos, quando moços, afirmou, certa feita, que tôda a revolução autêntica se inicia graças a uma mudança de atitude em face dos problemas.

Ora, a obra renovadora dos mestres de processo em São Paulo é o fruto de uma mudança de atitude perante as questões sociais e econômicas de nossa época, atitude caracterizada pela conciliação dos ensinamentos dos mestres alemães e italianos, como Wach, von Bülow, Goldschmidt, Chiovenda, Carnelutti e Calamandrei, com as velhas e sempre vivas lições dos praxistas reinóis, e que no Brasil já se produziu de excelente nesta disciplina, com Paula Batista e Ramalho, João Mendes Júnior e João Monteiro.

É nisso que consiste a originalidade de seus estudos, razão pela qual, no velho tronco da robusta tradição jurídica luso-brasileira, se enxertam as contribuições das conquistas mais atuais do pensamento juridico europeu.

Tudo isto foi possível porque V.Exa. não é o produto de uma especialização prematura. Quando a circunstância ou a vocação inclinaram o seu espírito para o domínio do Direito Processual, a especialização não representou mais do que uma concentração total de energias no âmbito de uma determinada disciplina jurídica. $O$ especialista não é, nem pode ser, o produto de um deformante desdobramento da personalidade, visto como esta sempre se mantém integra, por mais que nosso intelecto se concentre na descoberta ou no desdobramento de verdades especiais.

Foi com essa orientação, com êsse cabedal de experiência humana, que V.Exa. iniciou as suas atividades, como livre docente nesta Casa, e depois, como catedrático da pontifícia Universidade Católica, conquistando, desde logo, os seus discipulos.

Não há, em verdade, correspondência mais extraordinàriamente comovente do que a dos alunos quando se defrontam com um mestre autêntico. Desde as primeiras aulas, os discípulos percebem a presença de um amigo e de um mentor no plano da cultura, retribuindo, em esfôrço 
e em dedicação, o esfôrço e a dedicação do mestre. Para êste não existe maior paga, nem maior confôrto espiritual, do que sentir que as suas aulas não são um monólogo, mas um diálogo vivo que penetra a consciência e se fixa na memória.

É só dessa forma que se consolidam as reputações culturais e se dignificam os institutos de ensino: pela linha de continuidade intelectual, pelo respeito ao passado, e pela projeção serena no sentido do futuro.

São estas as observações que desejo fazer, neste instante de tanta emoção para ambos, reconhecendo que a sua obra jurídica, professor Alfredo Buzaid, está embebida de sentido histórico, pela vivência do passado como presente, por saber alimentar-se dos modelos das gerações passadas, e à luz dêles, esculpir novas estruturas para o pensamento jurídico.

É a razão pela qual esta Congregação acolhe V.Exa. com entusiasmo e com confiança, na certeza de que a conquista da Cátedra não será o têrmo final de uma jore nada, um motivo para tranqüilo repouso, mas, ao contrário, uma razão a mais para a perserverança do trabalho, para novas realizações, para novos progressos, para novas arremetidas do espírito".

\section{Oração do Professor Alfredo Buzaid}

Após a saudação do prof. Miguel Reale pronunciou o prof. Alfredo Buzaid o seguinte discurso de agradecimento:

"Quando há dias tomei da pena para escrever êste discurso de agradecimento, confesso-vos que algo de estranho me invadiu a alma, deixando-me perplexo e confuso, conquanto por mais de um decênio aninhasse, entre os meus sonhos mais ousados, o de ser professor nesta Faculdade, só agora, admitido em vossa companhia, depois de vencer as duras provas do concurso, compreendi que o destino, em caprichoso enlêio, me reservara uma surprêsa, como que 
para agravar a responsabilidade desta investidura. Das três cadeiras de Direito Judiciário Civil, a que me tocou pertencera a João Mendes Júnior.

A ciência do processo refulge em São Paulo, no primeiro quartel dêste século, especialmente na obra de João Mendes Júnior, que cedo procurou libertar-se das regras estéreis da praxe e elevar-se à eminência dos princípios, a fim de construir a dogmática jurídica. $O$ sábio mestre era antes filósofo do que técnico; e, embuído de conceitos aristotélico-tomistas, reestruturou a teoria geral do processo, aplicando-lhe as noções de substância, acidente e movimento. $O$ que inquietava o seu espírito era o desejo de investigar as cousas pelas suas causas e iluminar os institutos pela cuidadosa análise de sua evolução. $O$ historiador completa assim o filósofo.

Sucede-lhe na cátedra Manuel Aureliano de Gusmão. Apesar de ter exercido por pouco tempo o magistério superior, deixou uma obra fundamental _- o "Curso de Processo Civil", em que revelou, além de ampla informação doutrinária, a segurança de idéias, expostas com clareza, concisão e simetria. Pouco depois de seu falecimento, ascende à cátedra Francisco Antônio de Almeida Morato. Quem o não conheceu? A natureza foi-lhe pródiga. Dotado de inteligência invulgar, cultivou o Direito Judiciário Civil por largos anos, escrevendo obras em que a elegância da linguagem rivalizava com a profundidade dos conceitos. Aposentando-se pela compulsória da idade, rege a cadeira por algum tempo Noé de Azevedo, penalista de grande renome, que manteve, pela sua ilustração e cultura, o nível alto dos mestres anteriores. Finalmente, em 1940, Benedito de Siqueira Ferreira conquista a cátedra, que ocupou com zêlo e dedicação. Sua tese de concurso -- Da Natureza Jurídica da Ação - aparece no momento decisivo, em que o direito brasileiro se integra na nova corrente de idéias difundidas pela cultura européia, cujos bruxulêios já haviam repontado em obras de mestres desta Casa. 
Coincide com êsse fecundo período de intensa inquietação a vinda de mestres estrangeiros, banidos de suas pátrias por perseguição étnica. Um dêles foi Enrico Tullio Liebman. Recebido carinhosamente nesta Escola, foi contratado para reger um curso de extensão universitária, que afortunadamente se prolongou por mais de um lustro. $O$ mestre não se limitou a dar as aulas no curso regular. Tornando-se amigo de um grupo que dêle se acercou, instituiu uma espécie de seminário, que se reunia todos os sábados em sua casa. Participamos do seminário, juntamente com Luís Eulálio de Bueno Vidigal, José Frederico Marques, Benvindo Aires e Bruno Afonso de André.

Os estudos de Direito Processual Civil, até o advento do mestre, tinham, salvo raras exceções, caráter acentuadamente individualista e auto didático. Os professôres brasileiros eram produtos de esfôrço próprio. Não criavam escola. Liebman compreendeu logo que a sua missão mais importante era formar um grupo de discípulos que, dominando a moderna metodologia, se tornassem aptos a trabalhar cientificamente. Dentre nós ressaltou-se, em primeiro lugar e por merecimento indiscutível, Luís Eulálio de Bueno Vidigal que, em 1953, conquista a cátedra de Direito Judiciário Civil, com a monografia sôbre "Mandado de Segurança", que é uma contribuição original do mais alto valor científico. Dêste eminente Mestre pode dizer-se que madrugou para a ciência do processo, pois, ainda jovem, ao escrever, em 1940, sua tese sôbre "Execução direta das obrigações de prestar declaração de vontade", revelou, já pela simples escolha do tema, notável maturidade de espírito, e, pelo largo tratamento da matéria, o descortino de um profundo investigador.

$O$ influxo das novas idéias encontra um realizador em Braz de Souza Arruda, que, na Diretoria, sem tardança, funda o curso de Prática Forense, inicialmente frequentado por poucos e em pouco tempo frequentado por muitos, vindo a ser uma sementeira de excelentes frutos. Este 
notável diretor realizava assim um ideal que sonhara vinte anos antes. A continuação dêsses trabalhos está confiada atualmente ao nosso infatigável colega, José de Almeida Amazonas, expressão de juventude perene, já que o ilustre professor Moacir Amaral Santos assumiu a regência da cadeira, vaga pelo falecimento do querido e saudoso mestre Gabriel de Rezende Filho, de quem fui discípulo e cujas aulas ficaram insculpidas para sempre em minha memória.

Ao assumir, neste ato soleníssimo, a cadeira que os meus nobres antecessores iluminaram com o esplendor do seu saber, recordo, com certo desvanecimento, os meus doze anos de docência livre. O contacto diuturno convosco fortaleceu antigas amizades e fêz nascer novas, de que muito me honra. O período da docência livre é fecundo de lições, porque nele muito mais se aprende do que se ensina. Do convívio com os caros colegas da docência livre, muito fiquei a dever a Alberto Muniz da Rocha Barros, Nicolau Nazo, Dimas de Oliveira Cesar, Marota Rangel e especialmente a Genésio de Almeida Moura, a quem recorri, vêzes sem conta, para dissipar dúvidas de interpretação de difíceis textos alemães.

Sr. Diretor! Peço venia para dizer de meu júbilo ao prestar êste compromisso perante V.Exa.. A vossa vida é um testemunho de trabalho, ordenado sério e diligente. As vossas obras, escritas com elegância e rigor de técnica, revelam a meditação do homem de gabinete, que nunca se divorciou do mundo das realidades.

Ouvi, profundamente comovido, a saudação proferida por Miguel Reale. A êste mestre insigne, que é um dos maiores filósofos do direito na América, estou vinculado por laço fraternal, cujas raízes mergulham nos bancos acadêmicos. Os votos de boas vindas, que êle apresentou em nome desta douta Congregação, não significam para mim uma manifestação meramente protocolar, antes o sêlo de uma velha amizade que jamais se apagará. Eu gostaria, se isso não quebrasse os estilos desta solenidade, de 
poder narrar episódios expressivos, que mostram quão profundo é o vínculo que me une a todos vós, e, assim, agradecer a cada um nominalmente. Mas, não sendo isso possivel, rogo que aceiteis o preito de minha eterna gratidão, pelo encorajamento na atividade intelectual que, dentro e fora desta Casa, procurei realizar.

Permiti-me, no entanto, que lembre, por considerações especiais, dois civilistas de escol: Jorge Americano, que duas vêzes me examinou em concurso à cátedra, aqui e na Faculdade Paulista de Direito; nele vejo o modêlo do jurista de fina intuição; e Lino de Morais Leme, que, em razão de particular afeto, foi mais do que o mestre; o amigo constante, cujas mercês, o livre docente de ontem e o catedrático de hoje, guardará no fundo de seu coração.

Egrégia Congregação! Vós me abristes definitivamente as portas desta augusta Academia. Eu vos abri o meu coração, para confidenciar os amores de um docente livre que esperou doze anos esta hora culminante. Não vos trago um programa. Mas um passado de trabalho intenso já é uma promessa; e só peço a Deus que me dê saúde para não interromper minha dedicação às letras jurídicas, porque nada me humilharia tanto como vir a ser o fundo de uma noite, onde brilha uma constelação de estrelas. 